\title{
TRACER STUDY INVESTIGATION INTO HYDRODYNAMIC VORTEX SEPARATOR CHARACTERIZATION
}

\author{
A. E. Enbaia ${ }^{1, *}$, S. M. Algarmadi ${ }^{2}$ \\ ${ }^{1}$ Petroleum Engineering Department, School of Engineering and Sciences, \\ Curtin University.CDT 250, 98009, Miri, Sarawak, Malaysia \\ ${ }^{2}$ Geology Department, Faculty of Sciences, Liverpool University, Liverpool, \\ United KingdomEmail: s.elgarmadi@liv.ac.uk
}

Received 20 November 2012, accepted 11 December 2012

\begin{abstract}
This study describes the macromixing within a hydrodynamic vortex separator and considers its potential as a disinfectant contact tank. It is typically used in the sedimentation process during the treatment of sewage. The macromixing was investigated by conducting tracer experiments from which are retention time distribution was obtained and interpreted to characterize the mixing. The separator was operated in a continuous mode with no base flow, and the retention-time distribution was obtained using a pulse input for a range of the flow-rates. The method of moments was used to obtain various functions such as axial dispersion and tanks-in-series model parameters. The study revealed that the HDVS is best treated as an imperfect plug-flow mixing device with a large amount of dispersion.
\end{abstract}

Keywords: Hydrodynamic vortex separator; axial dispersion model; retention time; tanks-in-series model

\section{Introduction}

Basically, the treatment of sewage is addressed by two European Union (EU) Directives, the urban wastewater treatment Directive; (Council of European Communities, 1991[1]) and the bathing water Directive;(Council of European Communities, 1991[2]). At present, no EU legislation specifically controls or requires the use of sewage disinfection processes to meet microbiological standards. However, there is increasing concern about the quantitative and qualitative nature of sewage and storm-sewage and the associated costs and practicalities of the traditional approaches. There is an emphasis on innovative methods for achieving cost-effective sewage treatment. This is highlighted in the proposed amendments to the bathing water Directive; (Council of European Communities, 1991[2]). Which propose lower statutory limits in various microbiological indicators and extend the present definition of bathing water. If implemented, this would then include many inland waters and would mean that discharge consents could fail EU microbiological standards. The combined effect of these amendments and impending legislation could mean that the use of disinfectants is an option that many of the water undertakers would consider.

This study investigates the potential use of a hydrodynamic vortex separator (HDVS) as a mixing device for chemical disinfection. The device was first used in the 1960s.

\footnotetext{
* Corresponding author.

E-mail address:enbaia1972@gmail.com
} 
A. E. Enbaia, S. M. Algarmadi, Tracer study investigation into hydrodynamic vortex separator characterization, pp. $1352-1363$

\section{Hydrodynamic vortex separator}

The HDVS Figure 1 and Photo1, is normally considered as a vortex-style separating device which provides a controlled flow regime for the separation of solids from a liquid inlet stream. However, the HDVS can be used as a mixer. The mixing patterns within the device are provided by the position of the intake pipe, fixed geometry and internal configuration (Andoh and Smisson, 1994 [3]). The HDVS has two modes of operation, depending upon its application, i.e. with and without a base flow (Figure 1). When the HDVS is used as a mixing device it is typically operated with zero base flow and for solid / liquid separation with a base flow component.

The separation of solids from a liquid is mainly achieved, by extending the flow path, which a particle takes and hence provides more time for gravitational forces to act, and these are aided by inertial and other forces. A secondary flow pattern is superimposed on top of the primary flow as a result of the velocity gradients which are established. This assists in sweeping solids towards the sludge hopper in the base of the device, and provides a controlled flow regime for optimum solids separation (Andoh and Harper, 1993[4]). The treated water leaves the device through the overflow at the top (Figure 1 and Photo 1).

The HDVS is generally used on sewage-treatment plants, and its other main application is as a combined-sewer overflow (CSO). Its purpose is to control the quantity of flow; (a) passed forward to the treatment works, and (b) discharged to the receiving watercourse during wet-weather flows.

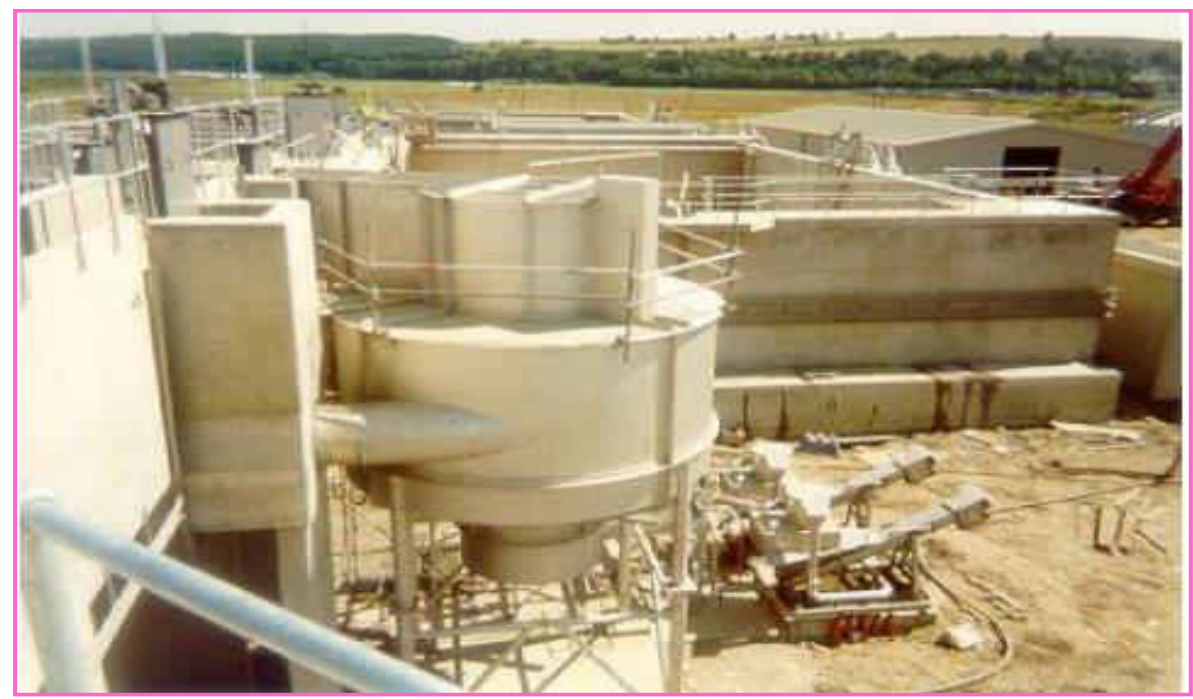

Fig.1.Configuration of hydrodynamic separator

Journal of Engineering Sciences, Assiut University, Faculty of Engineering, Vol. 41, No. 3, May, 2013,E-mail address: jes@aun.edu.eg 


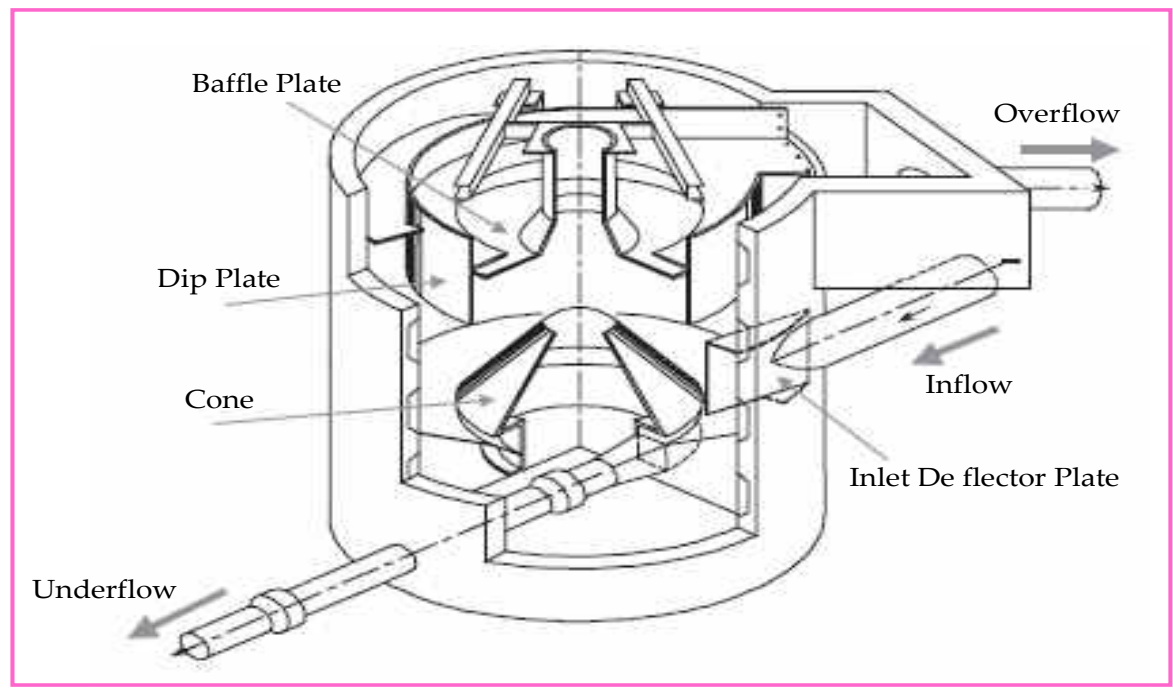

Photo 1. Hydrodynamic vortex separator

\section{Objective of study}

This study aimed to characterize the HDVS as a mixing device, with particular consideration to chemical processes used for tertiary treatment in the water industry. This was achieved by characterizing the macromixing within the HDVS by investigating the retention-time distribution (RTD). The RTD defines the time that different fluid elements remain in the HDVS. The experimental RTD was then compared with the theoretical mixing regimes of plug-flow and complete-mix, and any differences are as a result of nonideal mixing. This is considered to be the first stage in assessing the HDVS potential as a contact tank. Further investigations into kinetic and rate law data can then be directly interpreted and the HDVS performance optimized.

\section{Literature review}

The history, operation, designs and performance of the HDVS has been well documented by(Andoh and Smisson, 1994 [3] and Fagan, 1993 [5]). Most researcheshave investigated the level of physical/primary treatment provided by the device, i.e. the removal of suspended solids (SS) and biochemical oxygen demand (BOD); this has provided performance relationships for the design of the device as a solids-liquid separator. A full-scale programme is being carried out at Columbus, Georgia (in the USA) using HDVSs to investigate a range of treatment technologies and, specifically, methods used for tertiary treatment.

Trials at Columbus (Boner, 1993[6] and Dudley and Marks, 1993 [7]) have shown that the HDVS with sodium hypochlorite as the disinfectant provides equivalent treatment using approximately one-third of the volume of a tank as a mixer. The results of the data

Journal of Engineering Sciences, Assiut University, Faculty of Engineering, Vol. 41, No. 3, May, 2013, E-mail address: jes@aun.edu.eg 
A. E. Enbaia, S. M. Algarmadi, Tracer study investigation into hydrodynamic vortex separator characterization, pp. $1352-1363$

for chemical disinfection, use the concentration (C) multiplied by contact time (T), "CT" relationship, for describing its performance. This higher disinfectant performance is associated with a higher removal of solids the reduction of volume due to the underflow and a mixing device, which operates in a plug-flow manner, i.e. better chlorine utilization. It was concluded that the flow regime in these separators exhibited good plug-flow characteristics and was conducive to effective contacting for disinfection (Boner, 1993[6]).

The only existing RTD data published for this of HDVS were from RTD tests conducted on two full-scale devices at two flow-rates and provide data on the tanks-in-series and axial dispersion models (Dudley and Marks, 1993 [7]) Other devices which operate in a similar manner include the Fluid-Sep ${ }^{\mathrm{TM}}$, the vortex overflow with peripheral spill, and the US Swirl concentrator. The operatic and performance of these devices have been compared elsewhere (Andoh, 1998 [8]).

\section{RTD and disinfection contact tanks}

The typical approach for designing disinfectant contact tanks is based upon batch-scale investigations and the Chick-Watson law (Stevenson, 1995 [9]). However, these batchscale tests are conducted under 'perfect' mixing conditions and do not take account of any non-ideal flow behaviour within the continuous-flow system. The WHO drinking-water recommendations illustrate the problem to the designer in that there is no indication as to whether the 'CT' values apply to a batch, mixed tank or other alternative situation (Stevenson, 1995 [9]). To provide an accurate representation of the full-scale plant, nonideal flow behaviour must be considered. This is usually carried out using the RTD which describes the macromixing patterns within the full-scale contact tank. Knowledge of the RTD and data from batch experiments enables the optimum disinfectant concentration and contact time to be determined. This will save costs with a device such as the HDVS which exhibits different RTDs at different contact times, changing significantly as the contact time is increased (Figure 2). The need for the determination of the RTD in ultraviolet, chlorination and ozone reactors has been recognized and tracer studies have been investigated (Quails et al; 1989 [10]; Hass, 1988 [11]; and Martin, 1992 [12]). Tracer studies and coloured dye observations have concluded that the HDVS approximates to a plug-flow mixing regime which is considered more conducive to disinfectant.

\section{Materials and methods}

The device under investigation is a 750-mm dia. HDVS. A horizontal pipe (about 24pipe diameters in length) directs the flow into the device, and at approximately 12-pipe diameters a dosing point is located for the RTD pulse injection. Inlet flow control is provided by a gate valve, and flow is measured by a calibrated turbine-style flow meter. This type of flow meter measures and records the volume of flow passed; therefore the total volume passed during an experiment can be measured and an average flow-rate can be calculated. In addition, the flow-rate was checked volumetrically at the overflow. All experiments were conducted with zero base flow, for a range of flow-rates $(0.25-8.01 / \mathrm{s})$, providing theoretical retention times of 1-30 min.

Journal of Engineering Sciences, Assiut University, Faculty of Engineering, Vol. 41, No. 3, May, 2013,E-mail address: jes@aun.edu.eg 
1356

A. E. Enbaia, S. M. Algarmadi, Tracer study investigation into hydrodynamic vortex separator characterization, pp. 1352 - 1363

In this study pulse-injection technique is used to the RTD. The RTD was obtained experimentally by injecting a tracer into the device's inlet pipe at $t=0$ and then measuring its concentration in the outlet stream (Overflow) as a function of time. The tracer was injected in the centre of the flow of the inlet pipe. Lithium chloride was used as the tracer for the pulse experiments and samples were analysed immediately after collection using an atomic-absorption spectrophotometer.

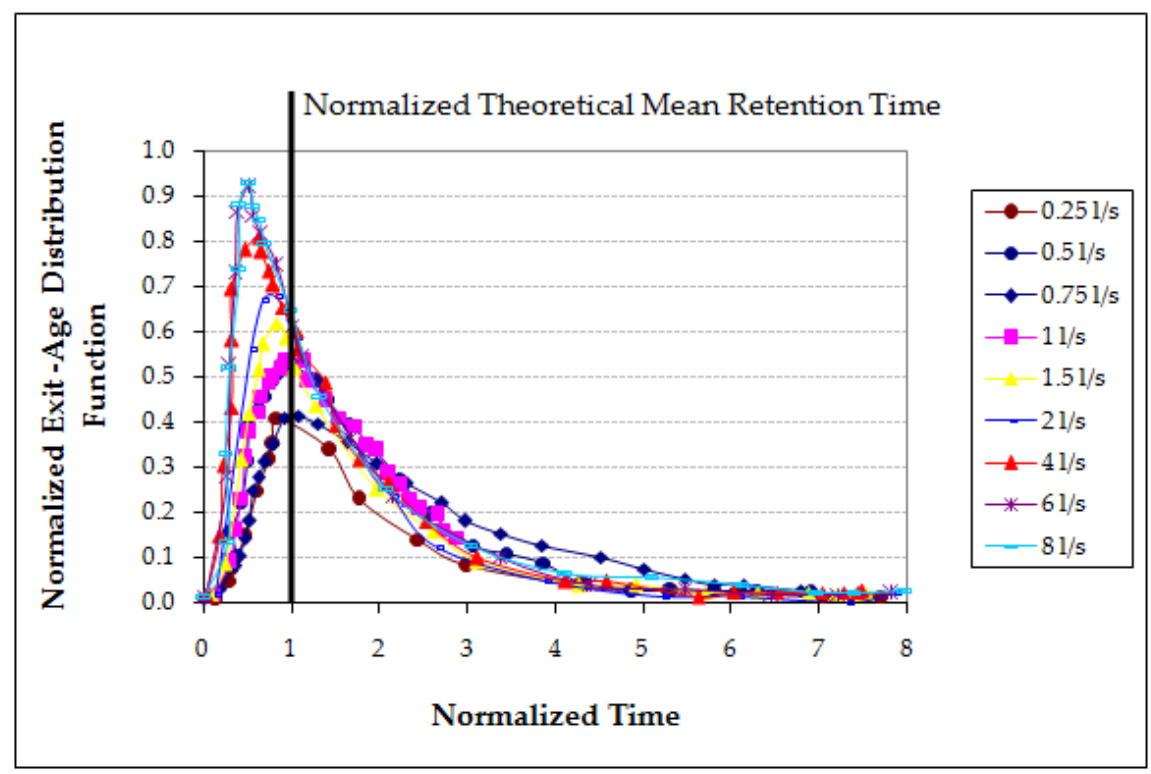

Fig.2.Comparison of normalized distribution curves

\section{Analysis of data}

The method of moments is used in this investigation to characterize the RTD of the device. To ensure consistency with RTD literature in chemical and environmental engineering, the same functions are used to describe the RTD (Levenspiel, 1972 [13]). The method of moments is used to determine the experimental mean retention time $\left(\mathrm{t}_{\mathrm{m}}\right)$, variance $\left(\sigma^{2}\right)$ and normalized variance $\left(\sigma \theta^{2}\right)$ which is the ratio of the variance to the square of the mean. The data are presented using the exit-age distribution function $E(t)$ :

$$
E(t)=\frac{C(t)}{\int_{0}^{\infty} C(t) d t}
$$

Where:

$E(t)$ is the fraction of material which has left the device between time $(t)$ and $(t+d t)$.

$\mathrm{C}(\mathrm{t})$ is the concentration of tracer measured at the overflow at time $(\mathrm{t})$.

The data are also presented in a normalized form. If the parameter $\Theta$ is defined as:

$\theta=\frac{t}{\tau}$ where $\tau=\frac{\text { Volume }}{\text { FlowRate }}$

Journal of Engineering Sciences, Assiut University, Faculty of Engineering, Vol. 41, No. 3, May, 2013, E-mail address: jes@aun.edu.eg 
A. E. Enbaia, S. M. Algarmadi, Tracer study investigation into hydrodynamic vortex separator characterization, pp. $1352-1363$

A dimensionless function $\mathrm{E}(\Theta)$ being defined as:

$E(\theta)=\tau E(t)$

And plotted as a function of $\Theta($ Fig 2$)$. The quantity $\Theta$ represents the number of reactor volumes of fluid which have passed through the reactor in time (t). The RTD in it's normalized from enables data for different flow-rates and reactors of different sizes to be compared directly. The experiments were stopped at 5-6 theoretical mean retention times, which are greater than the recommended 3-4 times (Nauman and Buffham, 1983 [14]). The mean retention time is calculated from the first moment (n) about the origin:

$\int_{0}^{\infty} \mathrm{E}(\mathrm{t}) \mathrm{tdt}$

The variance from the second moment about the mean:

$\sigma^{2}=\int_{0}^{\infty} E(t)\left(t-t_{m}\right)^{2} d t$

The normalized variance is used directly in predicting flow model responses, where (1) corresponds to complete mix and (0) to plug-flow:

$$
\sigma_{\theta}^{2}=\frac{\sigma^{2}}{t_{m}^{2}}
$$

All integrals used in the method of moments were solved using the trapezoidal rule. When calculating the moments, this is considered to have less bias than the moment of inertia approach (Hass, 1996 [15]).

Two single-parameter flow models are used in this investigation: the axial dispersion model (ADM) and tanks-in-series model (TISM). These two models have been used frequently in environmental engineering and will therefore allow comparison of the HDVS with other mixing devices. The TISM arises from a system of perfectly mixed tanks in series with fluid flowing from one tank to the next. The model parameter is $\mathrm{N}$, which is the equivalent number of tanks in series. When $\mathrm{N}=1$, the device under investigation is equal to one stirred tank and, as $\mathrm{N}$ increases, the mixing regime more closely approximates plugflow, the model is described as follows (Levenspiel, 1972 [13]).

$$
\mathrm{E}(\mathrm{t})=\left(\frac{\mathrm{N}^{\mathrm{N}} \times \mathrm{t}^{\mathrm{N}-1}}{\mathrm{t}_{\mathrm{m}}^{\mathrm{N}} \times(\mathrm{N}-1) !}\right) \exp \left(\frac{-\mathrm{N} \times \mathrm{t}}{\mathrm{t}_{\mathrm{m}}}\right)
$$

The normalized variance is related to the TISM parameter $\mathrm{N}$ by:

$$
\mathrm{N}=\frac{1}{\sigma_{\theta}^{2}}
$$

The ADM model is characterized using a dispersion number or its inverse, the Peclet number $(\mathrm{Pe})$. A $(\mathrm{Pe})$ value of less than 10 corresponds to a mixing regime with high dispersion and $(\mathrm{Pe})$ greater than 100, low dispersion. Since its exact solution is inconvenient to use, the approximation below is used Nauman and Buffham, 1983[14]. For disinfection contactors, the closed-closed boundary conditions for the ADM model are regarded as appropriate (Teefy and Singer, 1990 [16]).

$$
\mathrm{E}(\mathrm{t})=\left(\sqrt{\frac{\mathrm{t}_{\mathrm{m}}}{2 \pi \mathrm{t}^{3} \times \sigma_{\theta}^{2}}}\right) \exp \left(\frac{\left(\mathrm{t}-\mathrm{t}_{\mathrm{m}}\right)^{2}}{2 \mathrm{t}_{\mathrm{m}} \times \mathrm{t} \times \sigma_{\theta}^{2}}\right)
$$

This approximate relationship, used for the ADM, has an error of approximately $5 \%$ for a Peclet number of 5 (Hass, et al; 1997 [17]).

$$
\sigma_{\theta}^{2}=\left(\frac{2}{P_{\mathrm{e}}}\right)-\left(\frac{2}{\mathrm{P}_{\mathrm{e}}^{2}}\right)\left(1-\mathrm{e}^{-\mathrm{P}_{\mathrm{e}}}\right)
$$

Journal of Engineering Sciences, Assiut University, Faculty of Engineering, Vol. 41, No. 3, May, 2013,E-mail address: jes@aun.edu.eg 
1358

A. E. Enbaia, S. M. Algarmadi, Tracer study investigation into hydrodynamic vortex separator characterization, pp. $1352-1363$

The ADM and TISM are only two of a number of flow models used to characterize the form of the RTD (Levenspiel, 1972 [13]; Wen and Fan, 1975 [18]).

\section{Discussions}

Figure2shows a comparison of the normalized exit-age-distribution function $E(\Theta)$, for the range of flow-rates investigated. These curves illustrate plug-flow mixing with a degree of non-ideal flow behaviour. This is evidenced by a significant peak on the curve; however, some of the tracer leaves the device before the theoretical mean retention time $(\tau)$. There is also a significant tailing effect of the curve, with tracer detected at approximately 6 times the theoretical mean retention time. These effects demonstrate that stagnancy is present, resulting in dead spaces and some degree of short-circuiting within the device sameas described by (Levenspiel, 1972 [13]).

In Fig 2 it's appear to be two sets of curves with the transition point at approximately $1.51 / \mathrm{s}$. The first set of curves $(2-81 / \mathrm{s})$ illustrates a stable flow regime for the range of flow-rates. At lower flow rates $(<1.51 / \mathrm{s})$, the largest fraction of tracer leaves close to the theoretical mean retention time, suggesting that the total volume is active in the mixing process.

Table 1 contains RTD first and second moments calculated using E (t) and the full experimental data, for all flow-rates investigated. The estimated experimental mean retention time is significantly greater than the theoretical mean retention time, with the largest error at lower flow-rates and longer contact times $(+44 \%)$.

For all experiments, the device was operated with zero base flow, and under these conditions the sludge hopper (Fig 1) behaves as a stagnant region. The mass balance and mean retention time data illustrate this effect.

\section{Table 1.}

Comparison of RTD first and second moments

\begin{tabular}{cccccc}
\hline \hline $\begin{array}{c}\text { Flow } \\
\text { rate } \\
(\mathbf{l} / \mathbf{s})\end{array}$ & $\begin{array}{c}\text { Theoretical mean } \\
\text { retention time (min) }\end{array}$ & $\begin{array}{c}\text { Mean retention } \\
\text { time (min) }\end{array}$ & $\begin{array}{c}\text { Variance } \\
\left(\mathbf{m i n}^{2}\right)\end{array}$ & $\begin{array}{c}\text { Mean retention } \\
\text { time error (\%) }\end{array}$ & $\begin{array}{c}\text { Mass } \\
\text { balance (\%) }\end{array}$ \\
\hline 0.25 & 30.9 & 67.4 & 1645.0 & +44 & 67 \\
0.5 & 15.4 & 26.5 & 246.8 & +42 & 71 \\
0.75 & 10.3 & 15.8 & 108.5 & +35 & 82 \\
1.0 & 7.7 & 10.6 & 45.8 & +27 & 96 \\
1.5 & 5.1 & 7.9 & 30.2 & +35 & 106 \\
2.0 & 3.8 & 4.6 & 12.5 & +18 & 90 \\
4.0 & 1.9 & 2.2 & 3.8 & +15 & 92 \\
6.0 & 1.2 & 1.5 & 1.3 & +15 & 100 \\
8.0 & 0.9 & 1.2 & 0.9 & +20 & 99 \\
\hline \hline
\end{tabular}

Table 2 details the two model parameters and normalized variance, the latter giving an indication of the flow regime relative to the extremes of perfect plug-flow and completeJournal of Engineering Sciences, Assiut University, Faculty of Engineering, Vol. 41, No. 3, May, 2013,E-mail address: jes@aun.edu.eg 
A. E. Enbaia, S. M. Algarmadi, Tracer study investigation into hydrodynamic vortex separator characterization, pp. $1352-1363$

mix. A value of "one" corresponds to complete mix and "zero" to perfect plug-flow. They all show a similar trend, as would be expected the trend being approximately exponential. The Peclet number (inverse of the dispersion number) indicates a plug-flow mixing regime and high dispersion (Levenspiel, 1972 [13]). The device is equivalent to 1.7-2.8 perfectly mixed tanks depending upon the flow-rate. The two model parameters decrease as the flow-rate increase, which implies that the flow regime more closely approximates plugflow at lower flow-rates, and dispersion and mixing effects decrease. The model parameters also support initial observations that there are two sets of curves, with the transition at approximately $1.51 / \mathrm{s}$. Taking an average value for the two sets of curves above and below $1.51 / \mathrm{s}$, for both parameters $\mathrm{Pe}=3.9, \mathrm{~N}=2.6$ and $\mathrm{Pe}=1.7, \mathrm{~N}=1.6$ respectively. Existing RTD data on full-scale devices also suggest a device with high, dispersion ( $\mathrm{Pe}=3.9-6.3$ ) equivalent to 2.5-4 tanks in series (Andoh, 1995[4]). This shows that the flow regime remains stable for any size and hence the scale-up of the RTD for this particular device. However, these full-scale tests were terminated at approximately 3-4 times the theoretical mean retention time. The effects of truncating the RTD for HDVS, when calculating the various parameters, would need to be taken into consideration in order to compare the data.

Table 2.

Comparison of model parameters calculated using moments

\begin{tabular}{cccc}
\hline \hline Flow rate $(l / s)$ & Normalized variance & Peclet number & N-Tanks \\
\hline 0.25 & 0.36 & 4.24 & 2.76 \\
0.5 & 0.35 & 4.42 & 2.84 \\
0.75 & 0.43 & 3.25 & 2.30 \\
1.0 & 0.40 & 3.63 & 2.48 \\
1.5 & 0.48 & 2.72 & 2.07 \\
2.0 & 0.57 & 1.98 & 1.75 \\
4.0 & 0.75 & 0.93 & 1.33 \\
6.0 & 0.58 & 1.91 & 1.72 \\
8.0 & 0.59 & 1.84 & 1.69 \\
\hline
\end{tabular}

Figures 3 and 4 compare the experimental exit-age distribution function, $\mathrm{E}(\mathrm{t})$, to the TISM (Eq. 7) and ADM (Eq.9), obtained using the experimental moments for 0.5 and 4.0 $1 / \mathrm{s}$ respectively. From a visual comparison of the curves, the ADM appears to more closely approximate the experimental RTD than the TISM. The best fit occurs as the flowrate increases, although the data for $1.51 / \mathrm{s}$ do not keep to this simple trend. It is interesting to note that this is at the suggested transition point between the two sets of curves previously identified, the best fit occurring at 2 and $41 / \mathrm{s}$. For a more comprehensive analysis of these data a quantitative description of the best fit is required (Teefy and Singer, 1990[16).

Journal of Engineering Sciences, Assiut University, Faculty of Engineering, Vol. 41, No. 3, May, 2013,E-mailaddress: jes@aun.edu.eg 
1360

A. E. Enbaia, S. M. Algarmadi, Tracer study investigation into hydrodynamic vortex separator characterization, pp. $1352-1363$

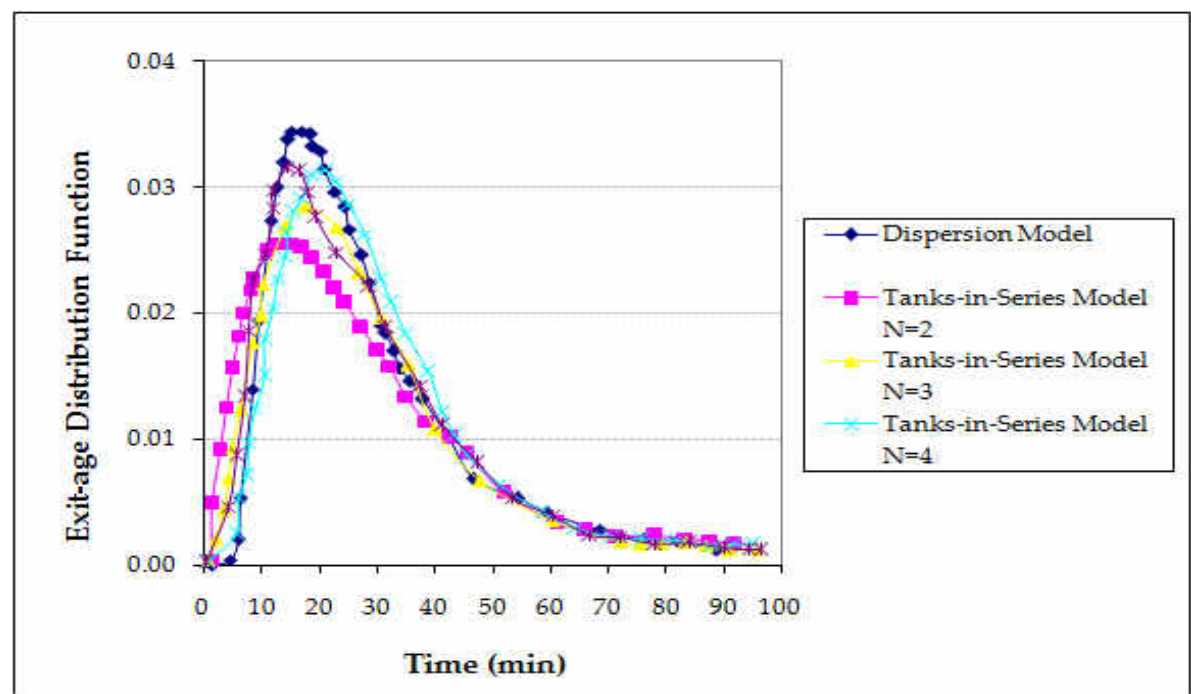

Fig.3.Comparison of experimental and model E (t) curves $(0.5 \mathrm{l} / \mathrm{s})$

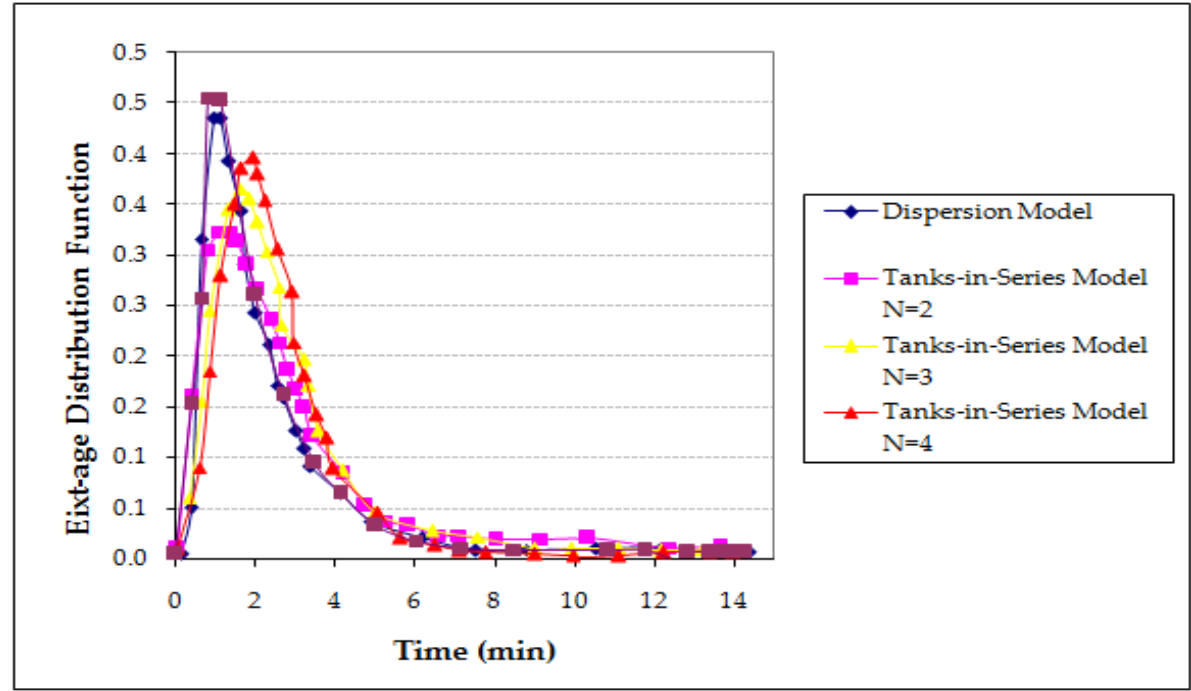

Fig.4.Comparison of experimental and model E (t) curves (4 1/s)

Journal of Engineering Sciences, Assiut University, Faculty of Engineering, Vol. 41, No. 3, May, 2013,E-mail address: jes@aun.edu.eg 
A. E. Enbaia, S. M. Algarmadi, Tracer study investigation into hydrodynamic vortex separator characterization, pp. $1352-1363$

\section{Conclusions}

1. The HDVS appears to provide a mixing regime which is conducive to efficient disinfection. The data enable any non-ideal flow behaviour to be accounted for when considering the operating parameters of the HDVS as a disinfection contact tank.

2. This study has shown that the HDVS is best treated as an imperfect plug-flow mixing device with a large amount of dispersion. The Peclet numbers (ADM).

3. The investigation has shown that there is a significant spread of retention times at all flow-rates; therefore current design methodology using the 'CT' concept may not ensure that the device is operating at its optimum, as the contact time is usually estimated from first principles.

4. The sludge hopper behaves as a stagnant region. This significantly affects all data analysis and, if the device is to be used as a contact tank, its performance may be improved by removing the sludge hopper.

5. This study has shown the importance of investigating the RTD for a range of flowrates. The normalized RTD curves for the HDVS change over the range of flowrates investigated. The design flow-rates range from approximately 0.5 to $3.01 / \mathrm{s}$, depending upon the application.

\section{Symbols and abbreviations}

RTD Residence Time Distribution

HDVS Hydrodynamic Vortex Separator

CSO Combined-Sewer Overflow

SS Suspended Solids

BOD Biochemical Oxygen Demand

C Concentration

$\mathrm{T} \quad$ Contact Time

1/s Litter per Second

Min Minutes

$\mathrm{t}_{\mathrm{m}} \quad$ Mean Retention Time

$\sigma^{2} \quad$ Variance

$\sigma_{\theta}{ }^{2} \quad$ Normalized Variance

$\mathrm{E}(\mathrm{t}) \quad$ Distribution Function

E $(\Theta)$ Dimensionless Function

ADM Axial Dispersion Model

TISM Tank in Series Model

$\tau_{\mathrm{m}} \quad$ Theoretical Mean Retention Time

\section{Acknowledgement}

The author wishes to thank Libyan Embassy London, Hydro Research and Development Ltd for providing technical support and funding.

Journal of Engineering Sciences, Assiut University, Faculty of Engineering, Vol. 41, No. 3, May, 2013,E-mail address: jes@aun.edu.eg 
A. E. Enbaia, S. M. Algarmadi, Tracer study investigation into hydrodynamic vortex separator characterization, pp. $1352-1363$

\section{References}

[1] Council of European Communities: "Directive concerning urban waste water treatment (91/271/EEC)" Official Journal / L135 / 40, 30 May 1991.

[2] Council of European Communities: "Directive concerning the quality of bathing water (76/160/EEC)" Official Journal / L31 / 1, 5 February 1991.

[3] Andoh, R. Y. G. and Smisson, R. P. M: "High-rate sedimentation in hydrodynamic separators" In 2nd int. Conf. on Hydraulic Modeling, Development and Application of Physical and Mathematical Models. Stratford, UK. 341. 1994.

[4] Andoh, R. Y. G. and Harper, I: "The Swirl-FloTM Process for high Rate PhysicoChemical Treatment at Wastewater Treatment Works" Hydro Research and Development Ltd. 1993.

[5] Fagan. G. W. A: "quality assessment of dynamic experiences: the UK experience" In Int. Conf. on Urban Storm Drainage. ICUSD, Canada Sept. 1993.

[6] Boner, M. C: "High-rate treatment of CSOs in Columbus, Georgia" In Int. Conf. on Urban Storm Drainage. ICUSD, Canada. Sept. 1993.

[7] Dudley, j. and Marks, H: "Evaluation of the Swirl-Flo"TM Process" Report No. UC 1869. Water Research Centre, Swindon. 728. 1993.

[8] Andoh R. Y. G: "Improving environmental quality using hydrodynamic vortex separators" Wat. Qual. Internat. 47, January / February 1998.

[9] Stevenson, D. G: "The design of disinfection contact tanks" J. Ch. Instn. Wat. \&Envir. Mangt, 9, (2), 146, 1995.

[10] Quails, R. G., Dorfman, M. H, and Johnson, j. D: "Evaluation of the efficiency of UV disinfection systems" Wat. Res., 23, (3), 317.1989.

[11] Haas, C. N: "Micromixing and dispersion in chlorine contact chambers" Envir. Technol. Letters. 9, (1), 35, 1988.

[12] Martin N: "Design and efficiency of ozone contactors for disinfection Ozone" Science and Engng. 14, (5), 391, 1992.

[13] Levenspiel, O: "Chemical Region Engineering" 2nd Edition, John Wiley \& Sons, Chichester. 1972.

[14] Nauman, E. G. and buffham, B. A: "Mixing in Continuous Flow Systems" f John Wiley \& Sons, Inc. New York. 1983.

[15] Haas, C. N: "Moment analysis of tracer experiments" J. Envir. Engng. (ASCE), 122, (12), 1121. 1996.

[16] Teefy, S. M. and Singer. P. C: "Performance arc analysis of Tracer tests 10 determines compliance of a disinfection scheme with the SWTR" Am. Wat. Wks. Assoc., 82, (12), 88. 1990.

[17] Haas, C. N., Joffe, J. And Heath, M. S: "Continuous flow residence time distribution function characterization" J. Envir. Engng. (ASCE), 123, (2), 107. 1997.

[18] Wen, C. Y. and Fan, L, T: "Models for Flow Systems and Chemical Reactors" Chemical Processing and Engineering, Vol. 3, Marcel. Dekker, Inc., New

Journal of Engineering Sciences, Assiut University, Faculty of Engineering, Vol. 41, No. 3, May, 2013, E-mail address: jes@aun.edu.eg 
A. E. Enbaia, S. M. Algarmadi, Tracer study investigation into hydrodynamic vortex separator characterization, pp. 1352 - 1363

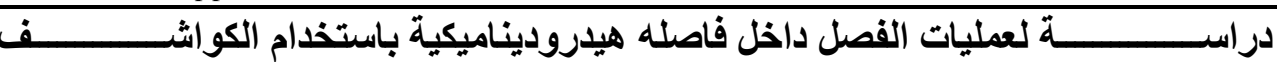
ملخص:

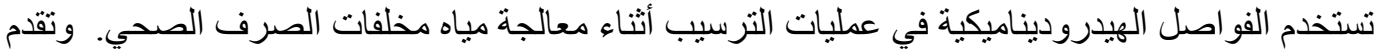

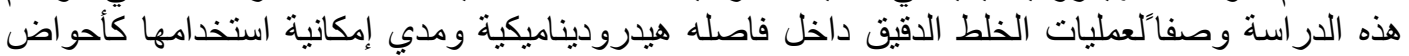

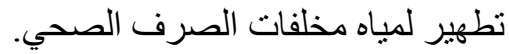
وتم إجر اء تجارب معمليه باستخدام الكو اشف لتتبع عمليات الخلط للحصول علي منحنيات زمن الاستقرار

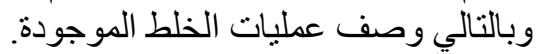

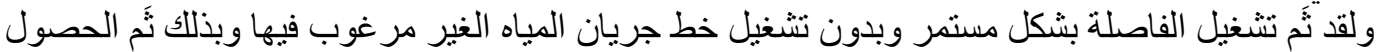

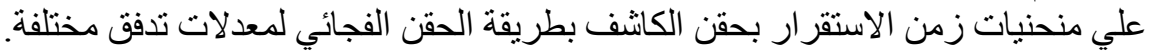

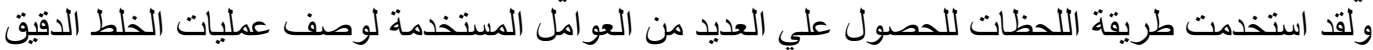

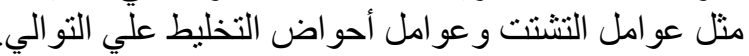
و أشارت هذه الدراسة إلى إمكانية استخدام الفاصلة للحصولية الحصول علي أفضل معالجة عندما تشتخل تحت ظروف تشتيت عالية جداً. 